University of South Florida

DIGITAL COMMONS

Digital Commons @ University of

@ UNIVERSITY OF SOUTH FLORIDA

South Florida

\title{
Urgent Need for Field Surveys of Coronaviruses in Southeast Asia to Understand the SARS-CoV-2 Phylogeny and Risk Assessment for Future Outbreaks
}

\author{
Murat Seyran \\ University of Vienna \\ Sk. Sarif Hassan \\ Pingla Thana Mahavidyalaya \\ Vladimir N. Uversky \\ University of South Florida, vuversky@usf.edu \\ Pabitra Pal Choudhury \\ Indian Statistical Institute, Kolkata \\ Bruce D. Uhal \\ Michigan State University \\ Follow this and additional works at: https://digitalcommons.usf.edu/usf_fcrc_all \\ See next page for additional authors
}

\section{Scholar Commons Citation}

Seyran, Murat; Sarif Hassan, Sk.; Uversky, Vladimir N.; Choudhury, Pabitra Pal; Uhal, Bruce D.; Lundstrom, Kenneth; Attrish, Diksha; Rezaei, Nima; Aljabali, Alaa A. A.; Ghosh, Shinjini; Pizzol, Damiano; Adadi, Parise; El-Aziz, Tarek Mohamed Abd; Kandimalla, Ramesh; Tambuwala, Murtaza M.; Lal, Amos; Azad, Gajendra Kumar; Sherchan, Samendra P.; Baetas-da-Cruz, Wagner; Palù, Giorgio; and Brufsky, Adam M., "Urgent Need for Field Surveys of Coronaviruses in Southeast Asia to Understand the SARS-CoV-2 Phylogeny and Risk Assessment for Future Outbreaks" (2021). All publications. 92.

https://digitalcommons.usf.edu/usf_fcrc_all/92

This Article is brought to you for free and open access by the USF Libraries Florida COVID-19 Research Collections at Digital Commons @ University of South Florida. It has been accepted for inclusion in All publications by an authorized administrator of Digital Commons @ University of South Florida. For more information, please contact digitalcommons@usf.edu. 


\section{Authors}

Murat Seyran, Sk. Sarif Hassan, Vladimir N. Uversky, Pabitra Pal Choudhury, Bruce D. Uhal, Kenneth Lundstrom, Diksha Attrish, Nima Rezaei, Alaa A. A. Aljabali, Shinjini Ghosh, Damiano Pizzol, Parise Adadi, Tarek Mohamed Abd El-Aziz, Ramesh Kandimalla, Murtaza M. Tambuwala, Amos Lal, Gajendra Kumar Azad, Samendra P. Sherchan, Wagner Baetas-da-Cruz, Giorgio Palù, and Adam M. Brufsky 


\title{
Urgent Need for Field Surveys of Coronaviruses in Southeast Asia to Understand the SARS-CoV-2 Phylogeny and Risk Assessment for Future Outbreaks ${ }^{\dagger}$
}

\author{
Murat Seyran ${ }^{1}$, Sk. Sarif Hassan ${ }^{2}\left(\right.$ ) , Vladimir N. Uversky ${ }^{3, *(D)}$, Pabitra Pal Choudhury ${ }^{4}$, Bruce D. Uhal ${ }^{5}{ }^{(0}$, \\ Kenneth Lundstrom 6,*, Diksha Attrish ${ }^{7}$, Nima Rezaei ${ }^{8,9}$, Alaa A. A. Aljabali $10 \mathbb{1}$, Shinjini Ghosh ${ }^{11}$, \\ Damiano Pizzol ${ }^{12}$ (D), Parise Adadi ${ }^{13}$ (D), Tarek Mohamed Abd El-Aziz ${ }^{14,15}$ (D), Ramesh Kandimalla ${ }^{16}$, \\ Murtaza M. Tambuwala ${ }^{17}$ (D) Amos Lal ${ }^{18}$, Gajendra Kumar Azad ${ }^{19} \mathbb{D}^{\mathbb{D}}$, Samendra P. Sherchan ${ }^{20}$, \\ Wagner Baetas-da-Cruz ${ }^{21}$ (D) Giorgio Palù ${ }^{22, *}$ and Adam M. Brufsky 23 (D)
}

1 Doctoral Studies in Natural and Technical Sciences (SPL 44), University of Vienna, Währinger Straße, A-1090 Vienna, Austria; a11851761@unet.univie.ac.at

2 Department of Mathematics, Pingla Thana Mahavidyalaya, Maligram, Paschim Medinipur 721140, West Bengal, India; sarimif@gmail.com

3 Department of Molecular Medicine, Morsani College of Medicine, University of South Florida, Tampa, FL 33612, USA

4 Applied Statistics Unit, Indian Statistical Institute, Kolkata 700108, West Bengal, India; pabitrapalchoudhury@gmail.com

5 Department of Physiology, Michigan State University, East Lansing, MI 48824, USA; bduhal@gmail.com

6 PanTherapeutics, Rte de Lavaux 49, CH1095 Lutry, Switzerland

check for updates

Citation: Seyran, M.; Hassan, S..S.; Uversky, V.N.; Pal Choudhury, P.; Uhal, B.D.; Lundstrom, K.; Attrish, D.; Rezaei, N.; Aljabali, A.A.A.; Ghosh, S.; et al. Urgent Need for Field Surveys of Coronaviruses in Southeast Asia to Understand the SARS-CoV-2 Phylogeny and Risk Assessment for Future Outbreaks. Biomolecules 2021, 11, 398. https://doi.org/10.3390/ biom 11030398

Received: 10 January 2021 Accepted: 20 February 2021 Published: 9 March 2021

Publisher's Note: MDPI stays neutral with regard to jurisdictional claims in published maps and institutional affiliations.

Copyright: (c) 2021 by the authors. Licensee MDPI, Basel, Switzerland. This article is an open access article distributed under the terms and conditions of the Creative Commons Attribution (CC BY) license (https:// creativecommons.org/licenses/by/ $4.0 /)$.
Dr. B R Ambedkar Center for Biomedical Research (ACBR), University of Delhi (North Camps), Delhi-110007, India; dikshaattrish@gmail.com

8 Research Center for Immunodeficiencies, Pediatrics Center of Excellence, Children's Medical Center, Tehran, University of Medical Sciences, Tehran 1419733151, Iran; rezaei_nima@yahoo.com

9 Network of Immunity in Infection, Malignancy and Autoimmunity (NIIMA), Universal Scientific Education and Research Network (USERN), Tehran 1419733151, Iran

10 Department of Pharmaceutics and Pharmaceutical Technology, Yarmouk University-Faculty of Pharmacy, Irbid 566, Jordan; alaaj@yu.edu.jo

11 Department of Biophysics, Molecular Biology and Bioinformatics, University of Calcutta, Kolkata 700009, West Bengal, India; shinjinighosh2014@gmail.com

12 Italian Agency for Development Cooperation-Khartoum, Sudan Street 33, Al Amarat 13374, Sudan; damianopizzol8@gmail.com

13 Department of Food Science, University of Otago, Dunedin 9054, New Zealand; pariseadadi@gmail.com

14 Department of Cellular and Integrative Physiology, University of Texas Health Science Center at San Antonio, 7703 Floyd Curl Dr, San Antonio, TX 78229-3900, USA; mohamedt1@uthscsa.edu

15 Zoology Department, Faculty of Science, Minia University, El-Minia 61519, Egypt

16 CSIR-Indian Institute of Chemical Technology Uppal Road, Tarnaka,

Hyderabad 500007, Telangana State, India; ramesh.kandimalla@gmail.com

17 School of Pharmacy and Pharmaceutical Science, Ulster University, Coleraine BT52 1SA, Northern Ireland, UK; m.tambuwala@ulster.ac.uk

18 Division of Pulmonary and Critical Care Medicine, Mayo Clinic, Rochester, MN 55905, USA; manavamos@gmail.com

19 Department of Zoology, Patna University, Patna 800005, Bihar, India; gkazad@patnauniversity.ac.in

20 Department of Environmental Health Sciences, Tulane University, New Orleans, LA 70112, USA; sshercha@tulane.edu

21 Translational Laboratory in Molecular Physiology, Centre for Experimental Surgery, College of Medicine, Federal University of Rio de Janeiro (UFRJ), Rio de Janeiro 21941901, Brazil; wagner.baetas@gmail.com

22 Department of Molecular Medicine, University of Padova, Via Gabelli 63, 35121 Padova, Italy

23 UPMC Hillman Cancer Center, Department of Medicine, Division of Hematology/Oncology, University of Pittsburgh School of Medicine, Pittsburgh, PA 15213, USA; brufskyam@upmc.edu

* Correspondence: vuversky@usf.edu (V.N.U.); lundstromkenneth@gmail.com (K.L.); giorgio.palu@unipd.it (G.P.)

+ All authors are the members of the Self-Assembled COVID Research and Education Directive (SACRED) Consortium.

Phylogenetic analysis of severe acute respiratory syndrome coronavirus 2 (SARS$\mathrm{CoV}-2$ ) is focused on a single isolate of bat coronaviruses (bat CoVs) which does not 
adequately represent genetically related coronaviruses (CoVs). The unique bat $\mathrm{CoV}$ RaTG13 is the only identified sequence genetically associated with SARS-CoV-2. Data scarcity of bat $\mathrm{CoV}$ sequences raises concerns over several fundamental experimental and biostatistical aspects, e.g., repeatability of sequences and intraspecies variations in critical gene regions, such as the receptor-binding domain of the spike protein. The Sunda pangolin has been proposed as the intermediate host and source of SARS-CoV-2, but no pangolin $\mathrm{CoV}$ isolates have been reported in its habitats in Southeast Asia. Most pangolin CoVs were isolated from pangolins captured during illegal animal trafficking, raising questions about such isolates' reliability and quality. Problems with pangolin CoV sampling are also related to the substandard quality of deposited sequences. There is an urgent need for field surveys of bat CoVs and possible intermediate hosts, such as pangolins, ferrets, and civets, in Southeast Asia to investigate the genomic source of SARS-CoV-2 and assess possible future risks for new outbreaks.

SARS-CoV-2 is the causative agent of the coronavirus disease 2019 (COVID-19) pandemic in which the first cases were reported in Wuhan, Hubei Province, China. SARSCoV-2, a member of Betacoronavirus and subgenus Sarbecovirus, is phylogenetically related to bat coronaviruses (bat CoVs) RaTG13 (detected in Pu'er City in 2013) and RmYN02 (detected in Xishuangbanna City in 2019) and were detected approximately $2000 \mathrm{~km}$ from Wuhan [1,2]. Betacoronavirus and its genetic reservoir bat species, such as the intermediate horseshoe bat Rhinolophus affinis, inhabit Southeast Asia [1,3,4]. It has been hypothesized that pangolin CoVs may have originated from cross-species transmission in bats [5]. To date, no additional bat CoVs RaTG13 or RmYN02 isolates and no pangolin CoV isolates originating from healthy or sick pangolins in their natural habitats in Southeast Asian countries have been sequenced (Figure 1). Therefore, here, we seek to draw the attention of relevant institutions toward the need to obtain $\mathrm{CoV}$ isolates from potential hosts, such as healthy or sick pangolins, in their natural habitats to match the existing sequences.

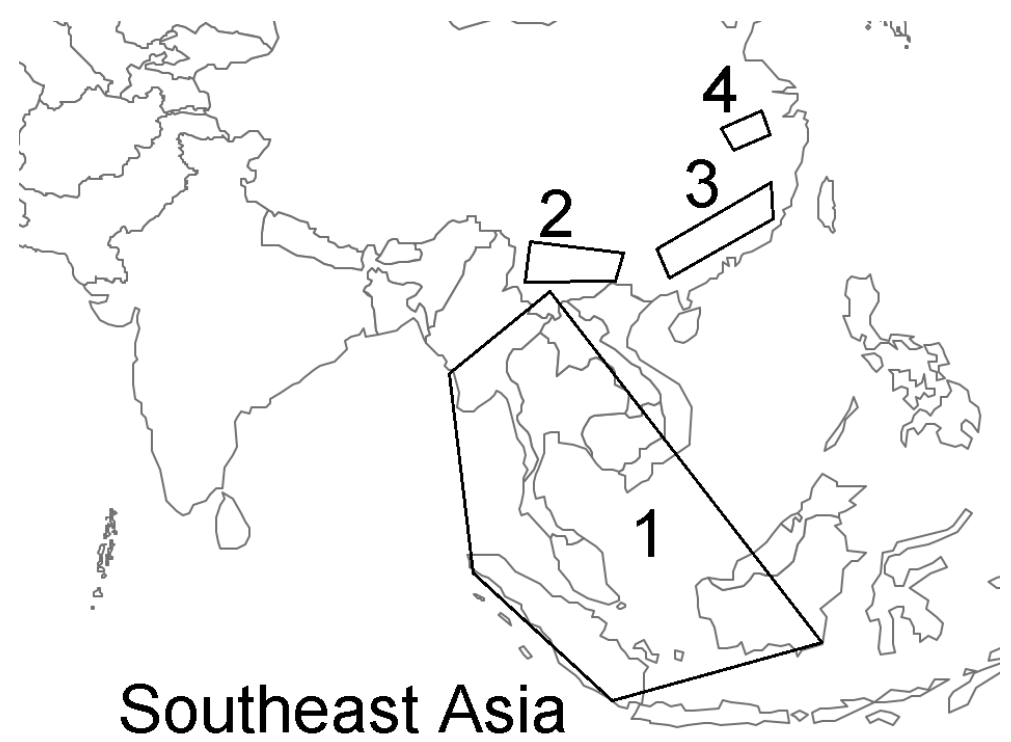

Figure 1. Zone 1 is the area where Sunda pangolins are distributed in Southeast Asia and the potential source area of severe acute respiratory syndrome coronavirus 2 (SARS-CoV-2) that has never been screened for genetically related clades of coronaviruses (CoVs). Zone 2 is the location where bat coronaviruses (bat CoVs) RaTG13 and RmYN02 were isolated in Yunnan, China. Zone 3 is where Sunda pangolin CoVs were isolated from dead pangolins in Guangxi and Guangdong, China. Zone 4 is the location where SARS-CoV-2 was first reported from its epicenter in Wuhan [3].

Based on genomic and sequence data submitted on pangolin CoVs in early 2020, pangolins were proposed as the intermediate host for SARS-CoV-2 [5-8]. Recent genomic analysis suggests the possible recombination of bat CoVs and pangolin CoVs, which occurred at least twice, leading to the creation of SARS-CoV- 2 [9]. Furthermore, pangolin 
cells lacking the interferon-induced helicase C domain 1 (IFIH1) and Z-DNA-binding protein (ZBP1) have been postulated to contribute to the switch from resistance to tolerance of $\mathrm{CoV}$ infections [10]. Pangolins such as the giant pangolin, Smutsia gigantea, inhabit the same caves as different bat species such as Hipposideridae sp., Emballonuridae sp., and Miniopterus sp. in Gabon, which could also be the case in Southeast Asia [11].

Illegal animal trafficking of infected pangolins has been postulated as the possible transmission route of SARS-CoV-2 to its epicenter at Wuhan's wet seafood animal market [6-8]. The Sunda pangolin (Manis javanica) is native to Southeast Asian countries, such as Cambodia, Myanmar, Thailand, Laos, Vietnam, and a small area in Yunnan, China, where the potential source of the SARS-CoV-2 intermediate horseshoe bat is also present $[1,3,12]$. Under these conditions, the Sunda pangolin would serve as the intermediate host, and SARS-CoV-2 would have emerged through spillover from pangolins to humans once (scenario I) or several times (scenario II) [5]. It is also possible that SARS-CoV-2 and pangolin CoVs would have originated independently through the crosstransmission of bat species (scenario III) [5]. Interestingly, pangolin CoVs have also been detected approximately $1000 \mathrm{~km}$ from Wuhan (Guangxi Province, 2017, and Guangdong Province, 2019) [6-8].

SARS-CoV-2 has been suggested to diverge from the lineage of bat CoV Ratg13 in 1969 , with the highest posterior density interval of $95 \%$ for the years 1930 to 2000 [13]. To date, no isolates other than bat CoVs RaTG13 and RmYN02 have been discovered, resulting in incomplete phylogenetic analyses, such as the selection of midpoint rooting, limited taxon sampling, and inappropriate emphasis on one single element such as ACE2 [14]. The intraspecies phylogeny of the SARS-CoV-2 clinical isolate has been criticized, and it has been requested to utilize larger datasets and sample variability, which are also required for the determination of the interspecies SARS-CoV-2 phylogeny with bat CoVs, e.g., RaTG13 [14,15]. Most phylogenetic studies ignore the necessity of sufficient intraspecies sample sizes and the assessment of intraspecies genomic variations [16].

The findings from comparative phylogenetic analyses can be influenced by intraspecies sample sizes [16], which might be the case for SARS-CoV-2. If the intraspecific genomic variation is high, a large dataset is necessary due to potential heterogeneity [16]. For instance, the pangolin CoVs and SARS-CoV-2 spike (S) protein receptor-binding domains (RBDs) are almost identical [8]. However, if the intraspecies variability in the S protein RBD of pangolin CoVs is high, the assessment of the genetic relatedness to SARS-CoV2 is unreliable. This also applies to the phylogenetic analysis of SARS-CoV-2 with bat $\mathrm{CoV}$ species.

However, if the $\mathrm{S}$ protein RBD in the SARS-CoV-2 clade can be considered as conserved, the genomic relatedness to RmYN02 is irrelevant since their RBD homology is low [2]. Similarly, based on a single sequence of RmYN02, the furin protease cleavage insert of SARS-CoV-2 was proposed [2,17]. If S1/S2 in the S protein of RmYN02 is a variable and a discrete trait of this viral species, these genetic conclusions are irrelevant [2].

Reproducibility, seasonality, population differences, and measurement errors of sequences of bat $\mathrm{CoVs}$ and pangolin $\mathrm{CoVs}$ have not been validated [2,6-8,13]. Additionally, there could be sequencing errors due to several factors such as poor sample quality, improper handling, secondary PCR enrichment, and low-quality measurements $[16,18]$. The RaTG13 strain was isolated in 2013, but its complete genomic sequence (GenBank ID MN996532) was submitted after the emergence of SARS-CoV-2 in 2020 [19]. Additionally, the RNA-dependent RNA polymerase (RdRp) gene of RaTG13 is identical to that of another bat $\mathrm{CoV}$ sequence BtCoV/4991 (GenBank ID KP876546) submitted in 2015 [19]. Strikingly, NCBI KRONA analysis of the RaTG13 sequence suggested the possibility of DNA contamination, and the sequence was considered a fossil record [7,20]. For example, the analysis relied on the pangolin CoV sequence MP789 on GISAID (https: //www.gisaid.org/EPI_ISL_412860hCoV-19/pangolin/China/MP789/2019, accessed on 14 September 2020). However, the database commented on sequences with long stretches of unreadable bases in nucleic acid sequences annotated as NNNs (about 7\%) and missing 
NSP14. Pangolin CoV MP789 was collected from the lungs of dead pangolins [7]. The sequencing was completed with gap-filling PCR, and the filled version was deposited in GenBank (MT121216.1) [7]. Although gap filling is a standard protocol, this indicates the need for better sample and sequence quality for pangolin CoVs. The gap filling had quality issues, missing data, and unexpected reads possibly due to contamination by other viruses, including SARS-CoV-2-related viruses, and mitochondrial genes from pangolins (NC_026781), humans (NC_012920), tigers (NC_010642), and mice (NC_005089) were identified [21]. Similarly, pangolin CoV isolate P3B, collected from Sunda pangolin blood, possesses long sequence stretches of unreadable NNNs ( $8 \%$ of the sequence), and NSP3, NSP2, NSP6, NSP4, NSP15, and NSP8 were missing in this sample. The sequence of P3B was characterized using a gap-filling protocol, but the completed sequence has not been deposited in GenBank [6].

Based on three single isolates of bat CoVs (RaTG13, ZC45, and ZXC21) and gap-filled pangolin CoV (2017 and 2019 isolates) sequences, it was postulated that SARS-CoV-2 diversified as a species 70 years ago and remained undetected [12]. These analyzed sequences are an insufficient representation of all genetically related sarbecoviruses to SARS-CoV-2 in Southeast Asia $[1,3,13]$. This raises the question of how the wild-type SARS-CoV-2 has existed for 70 years without infecting humans. Many people involved in the hunting and trade of pangolins should have been exposed to the SARS-CoV-2 ancestor before the Wuhan outbreak [12]. For instance, approximately 83 bat species are consumed in 33 different countries, including 13 species in New Guinea and 14 species in the Philippines [22]. Considering the high mobility of bat species consumed by humans as bushmeats, there is a high possibility of direct contact of humans with SARS-CoV-2 [1] Additionally, the higher risk of $\mathrm{CoV}$ transmission to other animals and humans is not due to meat consumption but contamination of water sources, since CoVs exist in bat feces [23]. For example, bats contaminated wells and ponds with MERS-CoV, which infected camels, leading to humans [23].

However, the reason why SARS-CoV-2 remained dormant for 70 years could be related to its different pathology in bats. CoVs like RaTG13 infect the bat gastrointestinal system, since they have been detected in the feces and intestines of bats [23]. Bats cope well with CoVs, eliciting robust amounts of antibody responses [23]. In a study conducted in Yunnan Province on feces from the Chinese rufous horseshoe bat Rhinolophus sinicus, CoV was detected only in 12 of the 164 samples [4]. Therefore, bat-mediated host tropism events could have lesser proximity than expected due to the low frequency of bat $\mathrm{CoV}$ infection. Moreover, in a study conducted in Malaysia from 2009 to 2019 on 334 Sunda pangolins, none of the samples were positive for CoVs as verified by PCR [24].

The SARS-CoV-2 host range has been evaluated based on the interaction with the ACE2 entry receptor [25-27]. Despite residues 24, 30, 34, 38, 82, and 354 being common in both human and pangolin ACE2 protein, the binding affinity is much lower for pangolin ACE2, indicating that pangolins are not an intermediate host for the COVID-19 pandemic [26,27]. Moreover, SARS-CoV-2 can use other entry pathways such as C-type lectin receptors (CLRs) and neuropilin [28]. Therefore, SARS-CoV-2 might be capable of infecting host species with an incompatible ACE2 protein structure, such as mice and chickens [25,27]. Moreover, the presence of SARS-CoV-2 has been serologically confirmed in minks (Neovison vison), cats (Felis catus), ferrets (Mustela putorius furo), Chinese tree shrews (Tupaia belangeri chinensis), rhesus macaques (Macaca mulatta), domestic pigs (Sus domesticus), cynomolgus or crabeating macaques (Macaca fascicularis), racoon dogs (Nyctereutes procyonoides), common marmosets (Callithrix jacchus), hamsters (Mesocricetus auratus), African green or vervet monkeys (Chlorocebus aethiops), dogs (Canis familiaris), fruit bats (Rousettus aegyptiacus), tigers (Panthera tigris), and lions (Panthera leo), along with mild or moderate infections in some species [29-37]. Most cases could be traced back to human-to-animal transmission, but in some cases, fatal infections with an animal-to-animal transmission in minks and cats were detected, which indicates the highly contagious nature of SARS-CoV-2 [38-41]. Even mink-to-human back-infections have been described [39]. Given the pathological 
potential of SARS-CoV-2, a field survey to acquire large complete-genome samples of $\mathrm{CoVs}$ for various inter- and intraspecies analyses is essential to investigate the zoonotic origin of SARS-CoV-2 or to discover genetic diversity/unity among various CoVs and especially sarbecoviruses in Southeast Asia [1,2]. Furthermore, it will enrich information in the existing bat $\mathrm{CoV}$ and pangolin $\mathrm{CoV}$ species pool, leading to the discovery of CoVs in other potential hosts and expanding intraspecies sampling.

The foundation of humankind is vulnerable in the context of the pathological capacity of CoVs, especially SARS-CoV-2, a member of the Sarbecovirus subgenus that is responsible for the ongoing COVID-19 pandemic [42]. Expanded intra- and interspecies sampling for bat CoV RaTG13 and pangolin CoVs in Southeast Asia seems to be a reasonable scientific step critical for reliably elucidating the phylogenetic composition of the Sarbecovirus subgenus and its members, which are genetically related to SARS-CoV-2 [1,2]. Multiple isolates from different locations, times, and hosts of bats, pangolins, and other potential populations of CoVs are essential for improving understanding of the adaptations, mutations, and recombination patterns of genetically related clades of SARS-CoV-2. Furthermore, if SARS-CoV-2 is unrelated to RaTG13, its true bat CoV ancestor is still awaiting to be discovered. Therefore, there is an urgent need for CoV surveys on bats and possible intermediate hosts in Southeast Asia to reliably investigate the SARS-CoV-2 ancestry and identify genetically related sarbecoviruses with a similar pathological capacity to prevent future $\mathrm{CoV}$ outbreaks [42].

Funding: This research received no external funding.

Conflicts of Interest: The authors declare no conflict of interest.

\section{References}

1. Olival, K.J.; Cryan, P.M.; Amman, B.R.; Baric, R.S.; Blehert, D.S.; Brook, C.E.; Calisher, C.H.; Castle, K.T.; Coleman, J.T.; Daszak, P.; et al. Possibility for reverse zoonotic transmission of SARS-CoV-2 to free-ranging wildlife: A case study of bats. PLoS Pathog. 2020, 16, e1008758. [CrossRef]

2. Zhou, H.; Chen, X.; Hu, T.; Li, J.; Song, H.; Liu, Y.; Wang, P.; Liu, D.; Yang, J.; Holmes, E.C.; et al. A Novel Bat Coronavirus Closely Related to SARS-CoV-2 Contains Natural Insertions at the S1/S2 Cleavage Site of the Spike Protein. Curr. Biol. 2020, 30, 2196-2203.e3. [CrossRef]

3. Wong, A.C.P.; Li, X.; Lau, S.K.P.; Woo, P.C.Y. Global Epidemiology of Bat Coronaviruses. Viruses 2019, 11, 174. [CrossRef]

4. Han, Y.; Du, J.; Su, H.; Zhang, J.; Zhu, G.; Zhang, S.; Wu, Z.; Jin, Q. Identification of Diverse Bat Alphacoronaviruses and Betacoronaviruses in China Provides New Insights into the Evolution and Origin of Coronavirus-Related Diseases. Front. Microbiol. 2019, 10, 1900. [CrossRef]

5. Han, G.Z. Pangolins Harbor SARS-CoV-2-Related Coronaviruses. Trends Microbiol. 2020, 28, 515-517. [CrossRef]

6. Lam, T.T.; Jia, N.; Zhang, Y.W.; Shum, M.H.; Jiang, J.F.; Zhu, H.C.; Tong, Y.G.; Shi, Y.X.; Ni, X.B.; Liao, Y.S.; et al. Identifying SARS-CoV-2-related coronaviruses in Malayan pangolins. Nature 2020, 583, 282-285. [CrossRef] [PubMed]

7. Liu, P.; Jiang, J.Z.; Wan, X.F.; Hua, Y.; Li, L.; Zhou, J.; Wang, X.; Hou, F.; Chen, J.; Zou, J.; et al. Are pangolins the intermediate host of the 2019 novel coronavirus (SARS-CoV-2)? PLoS Pathog. 2020, 16, e1008421. [CrossRef] [PubMed]

8. Xiao, K.; Zhai, J.; Feng, Y.; Zhou, N.; Zhang, X.; Zou, J.J.; Li, N.; Guo, Y.; Li, X.; Shen, X.; et al. Isolation of SARS-CoV-2-related coronavirus from Malayan pangolins. Nature 2020, 583, 286-289. [CrossRef] [PubMed]

9. Afrasiabi, A.; Alinejad-Rokny, H.; Lovell, N.; Xu, Z.; Ebrahimi, D. Insight into the origin of 5'UTR and source of CpG reduction in SARS-CoV-2 genome. bioRxiv 2020. [CrossRef]

10. Fischer, H.; Tschachler, E.; Eckhart, L. Pangolins Lack IFIH1/MDA5, a Cytoplasmic RNA Sensor That Initiates Innate Immune Defense Upon Coronavirus Infection. Front Immunol. 2020, 11, 939. [CrossRef] [PubMed]

11. Lehmann, D.; Halbwax, M.L.; Makaga, L.; Whytock, R.; Ndindiwe Malata, L.L.; Bombenda Mouele, W.; Momboua, B.R.; Koumba Pambo, A.F.; White, L.J.T. Pangolins and bats living together in underground burrows in Lopé National Park, Gabon. Afr. J. Ecol. 2020. [CrossRef]

12. Hassanin, A.; Grandcolas, P.; Veron, G. Covid-19: Natural or anthropic origin? Mammalia 2020, 85, 1-7. [CrossRef]

13. Boni, M.F.; Lemey, P.; Jiang, X.; Lam, T.T.; Perry, B.W.; Castoe, T.A.; Rambaut, A.; Robertson, D.L. Evolutionary origins of the SARS-CoV-2 sarbecovirus lineage responsible for the COVID-19 pandemic. Nat. Microbiol. 2020, 5, 1408-1417. [CrossRef]

14. Wenzel, J. Origins of SARS-CoV-1 and SARS-CoV-2 are often poorly explored in leading publications. Cladistics 2020, 36, 374-379. [CrossRef]

15. Mavian, C.; Pond, S.K.; Marini, S.; Magalis, B.R.; Vandamme, A.M.; Dellicour, S.; Scarpino, S.V.; Houldcroft, C.; Villabona-Arenas, J.; Paisie, T.K.; et al. Sampling bias and incorrect rooting make phylogenetic network tracing of SARS-COV-2 infections unreliable. Proc. Natl. Acad. Sci. USA 2020, 117, 12522-12523. [CrossRef] 
16. Garamszegi, L.Z.; Møller, A.P. Effects of sample size and intraspecific variation in phylogenetic comparative studies: A metaanalytic review. Biol. Rev. Camb. Philos. Soc. 2010, 85, 797-805. [CrossRef] [PubMed]

17. Seyran, M.; Pizzol, D.; Adadi, P.; El-Aziz, T.M.A.; Hassan, S.S.; Soares, A.; Kandimalla, R.; Lundstrom, K.; Tambuwala, M.; Aljabali, A.A.A.; et al. Questions concerning the proximal origin of SARS-CoV-2. J. Med. Virol. 2020, 93, 1204-1206. [CrossRef] [PubMed]

18. Ma, X.; Shao, Y.; Tian, L.; Flasch, D.A.; Mulder, H.L.; Edmonson, M.N.; Liu, Y.; Chen, X.; Newman, S.; Nakitandwe, J.; et al. Analysis of error profiles in deep next-generation sequencing data. Genome Biol. 2019, 20, 1-15. [CrossRef] [PubMed]

19. Segreto, R.; Deigin, Y. The genetic structure of SARS-CoV-2 does not rule out a laboratory origin: SARS-COV-2 chimeric structure and furin cleavage site might be the result of genetic manipulation. Bioessays 2020, 43, 2000240. [CrossRef]

20. Singla, M.; Ahmad, S.; Gupta, C.; Sethi, T. De-novo assembly of RaTG13 Genome Reveals Inconsistencies further Obscuring SARS-CoV-2 Origins. Preprints 2020. [CrossRef]

21. Hassanin, A. The SARS-CoV-2-like virus found in captive pangolins from Guangdong should be better sequenced. bioRxiv 2020. [CrossRef]

22. Mickleburgh, S.; Waylen, K.; Race, P. Bats as bushmeat: A global review. Oryx 2009, 43, 217-234. [CrossRef]

23. Drexler, J.F.; Corman, V.M.; Drosten, C. Ecology, evolution and classification of bat coronaviruses in the aftermath of SARS. Antivir. Res. 2014, 101, 45-56. [CrossRef] [PubMed]

24. Lee, J.; Hughes, T.; Lee, M.H.; Field, H.; Rovie-Ryan, J.J.; Sitam, F.T.; Sipangkui, S.; Nathan, S.K.; Ramirez, D.; Kumar, S.V.; et al. No Evidence of Coronaviruses or Other Potentially Zoonotic Viruses in Sunda pangolins (Manis javanica) Entering the Wildlife Trade via Malaysia. Ecohealth 2020, 17, 406-418. [CrossRef] [PubMed]

25. Alexander, M.R.; Schoeder, C.T.; Brown, J.A.; Smart, C.D.; Moth, C.; Wikswo, J.P.; Capra, J.A.; Meiler, J.; Chen, W.; Madhur, M.S. Predicting susceptibility to SARS-CoV-2 infection based on structural differences in ACE2 across species. FASEB J. 2020, 34, 15946-15960. [CrossRef] [PubMed]

26. Frutos, R.; Serra-Cobo, J.; Chen, T.; Devaux, C.A. COVID-19: Time to exonerate the pangolin from the transmission of SARS-CoV-2 to humans. Infect. Genet. Evol. 2020, 84, 104493. [CrossRef]

27. Wu, L.; Chen, Q.; Liu, K.; Wang, J.; Han, P.; Zhang, Y.; Hu, Y.; Meng, Y.; Pan, X.; Qiao, C.; et al. Broad host range of SARS-CoV-2 and the molecular basis for SARS-CoV-2 binding to cat ACE2. Cell Discov. 2020, 6, 1-12. [CrossRef]

28. Seyran, M.; Takayama, K.; Uversky, V.N.; Lundstrom, K.; Palù, G.; Sherchan, S.P.; Attrish, D.; Rezaei, N.; Aljabali, A.A.; Ghosh, S.; et al. The Structural Basis of Accelerated Host Cell Entry by SARS-CoV-2. FEBS J. 2020. [CrossRef]

29. Freuling, C.M.; Breithaupt, A.; Müller, T.; Sehl, J.; Balkema-Buschmann, A.; Rissmann, M.; Klein, A.; Wylezich, C.; Höper, D.; Wernike, K.; et al. Susceptibility of raccoon dogs for experimental SARS-CoV-2 infection. Emerg. Infect. Dis. 2020, 26, 2982-2985. [CrossRef]

30. Fritz, M.; Rosolen, B.; Krafft, E.; Becquart, P.; Elguero, E.; Vratskikh, O.; Denolly, S.; Boson, B.; Vanhomwegen, J.; Gouilh, M.A.; et al. High prevalence of SARS-CoV-2 antibodies in pets from COVID-19+ households. One Health 2021, 11, 100192. [CrossRef]

31. Hobbs, E.C.; Reid, T.J. Animals and SARS-CoV-2: Species susceptibility and viral transmission in experimental and natural conditions, and the potential implications for community transmission. Transbound. Emerg. Dis. 2020. [CrossRef] [PubMed]

32. Meekins, D.A.; Morozov, I.; Trujillo, J.D.; Gaudreault, N.N.; Bold, D.; Carossino, M.; Artiaga, B.L.; Indran, S.V.; Kwon, T.; Balaraman, V.; et al. Susceptibility of swine cells and domestic pigs to SARS-CoV-2. Emerg. Microbes Infect. 2020, 9, 2278-2288. [CrossRef]

33. McAloose, D.; Laverack, M.; Wang, L.; Killian, M.L.; Caserta, L.C.; Yuan, F.; Mitchell, P.K.; Queen, K.; Mauldin, M.R.; Cronk, B.D.; et al. From People to Panthera: Natural SARS-CoV-2 Infection in Tigers and Lions at the Bronx Zoo. mBio 2020, 11, e02220-20. [CrossRef] [PubMed]

34. Pollock, D.D.; Castoe, T.A.; Perry, B.W.; Lytras, S.; Wade, K.J.; Robertson, D.L.; Holmes, E.C.; Boni, M.F.; Kosakovsky Pond, S.L.; Parry, R.; et al. Viral CpG Deficiency Provides No Evidence That Dogs Were Intermediate Hosts for SARS-CoV-2. Mol. Biol. Evol. 2020, 37, 2706-2710. [CrossRef] [PubMed]

35. Schlottau, K.; Rissmann, M.; Graaf, A.; Schön, J.; Sehl, J.; Wylezich, C.; Höper, D.; Mettenleiter, T.C.; Balkema-Buschmann, A.; Harder, T.; et al. SARS-CoV-2 in fruit bats, ferrets, pigs, and chickens: An experimental transmission study. Lancet Microbe 2020, 1, e218-e225. [CrossRef]

36. Uversky, V.N.; Elrashdy, F.; Aljadawi, A.; Redwan, E.M. Household pets and SARS-CoV2 transmissibility in the light of the ACE2 intrinsic disorder status. J. Biomol. Struct. Dyn. 2020, 1-4. [CrossRef] [PubMed]

37. Xu, L.; Yu, D.D.; Ma, Y.H.; Yao, Y.L.; Luo, R.H.; Feng, X.L.; Cai, H.R.; Han, J.B.; Wang, X.H.; Li, M.H.; et al. COVID-19-like symptoms observed in Chinese tree shrews infected with SARS-CoV-2. Zool. Res. 2020, 41, 517-526. [CrossRef]

38. Gaudreault, N.N.; Trujillo, J.D.; Carossino, M.; Meekins, D.A.; Morozov, I.; Madden, D.W.; Indran, S.V.; Bold, D.; Balaraman, V.; Kwon, T.; et al. SARS-CoV-2 infection, disease and transmission in domestic cats. Emerg. Microbes Infect. 2020, 9, $2322-2332$. [CrossRef]

39. Oude Munnink, B.B.; Sikkema, R.S.; Nieuwenhuijse, D.F.; Molenaar, R.J.; Munger, E.; Molenkamp, R.; van der Spek, A.; Tolsma, P.; Rietveld, A.; Brouwer, M.; et al. Transmission of SARS-CoV-2 on mink farms between humans and mink and back to humans. Science 2020, 371, 172-177. [CrossRef] [PubMed] 
40. Musso, N.; Costantino, A.; La Spina, S.; Finocchiaro, A.; Andronico, F.; Stracquadanio, S.; Liotta, L.; Visalli, R.; Emmanuele, G. New SARS-CoV-2 Infection Detected in an Italian Pet Cat by RT-qPCR from Deep Pharyngeal Swab. Pathogens 2020, 9, 746. [CrossRef]

41. Zaeck, L.M.; Scheibner, D.; Sehl, J.; Müller, M.; Hoffmann, D.; Beer, M.; Abdelwhab, E.M.; Mettenleiter, T.C.; Breithaupt, A.; Finke, S.; et al. 3D reconstruction of SARS-CoV-2 infection in ferrets emphasizes focal infection pattern in the upper respiratory tract. bioRxiv 2020. [CrossRef]

42. Relman, D.A. Opinion: To stop the next pandemic, we need to unravel the origins of COVID-19. Proc. Natl. Acad. Sci. USA 2020, 117, 29246-29248. [CrossRef] [PubMed] 